\title{
PEMIKIRAN DAN GERAKAN ISLAM FUNDAMENTALIS
}

\author{
Moh. Syaeful Bahar, Rofii Ali \\ Fisip UIN Sunan Ampel Surabaya, \\ Sekolah Tinggi Ilmu Syariah Darul Falah Bondowoso \\ email: bosbahar@yahoo.com
}

\begin{abstract}
Abstrak
Fundamentalisme adalah sebuah ideologi keagamaan yang menekankan pada keberadaan teks wahyu ilahiyah apa adanya. Sehingga sebutan fundamentalis disepadankan dengan skripturalis karena ritual keagamaannya merujuk pada teks secara rigid. Secara etimologis istilah fundamentalisme dalam islam tidak ditemukan padanan katanya, namun dalam perspektif historis gerakannya identik dengan kaum khawarij dengan idiom takfirinya. Indonesia adalah salah satu Negara yang menjadi tempat penyebaran ideologi fundamentalisme, menyusup dalam ruang-ruang domestik dan publik pemerintahan dan organisasi sosial kemasyarakatan baik secara personal maupun komunal.
\end{abstract}

Kata Kunci : Fundamentalis, oppositonalisme

\section{Pendahuluan}

Agama Islam tidak mengenal istilah fundamentalisme, istilah ini tidak pernah ditemukan dalam bahasa Arab, Indonesia atau sejumlah bahasa umat Islam lainnya. Karena istilah ini mulanya muncul di Barat sebagai respon kalangan agamawan Kristen terhadap pertentangan antara ilmu dan Agama. ${ }^{1}$ Dengan berkembangnya studi orientalisme dan studi regional. Istilah modernisme dan fundamentalisme mulai masuk kedalam perbendaharaan kata di dunia Islam. Aplikasi istilah-istilah ini selanjutnya tidak lagi terbatas untuk gejala yang muncul di dunia Kristen, tetapi di gunakan untuk meliputi semua gejala keagamaan yang memperlihatkan cirri-ciri yang hampir bersamaan. $^{2}$

Sebenarnya fundamentalisme merupakan fenomena umum pada setiap agama, termasuk agama Islam. ${ }^{3}$ Seperti dalam kenyataannya istilah fundamentalisme benar-benar di

\footnotetext{
${ }^{1}$ Rifyal Ka'bah "Modernisme dan Fundamentalisme Ditinjau dari Konteks Islam”, Ulumul Quran, IV, 3 (1993), h. 25

${ }^{2}$ Rifyal Ka'bah, Busthani Said, "Reaktualisasi Ajaran Islam: Pembaharuan Agama Visi Modernis dan Pembaharuan Agama Visi Salaf. (Jakarta : Minarei, 1987), cet -1. h. 34

${ }^{3}$ Ilyas Ismail, “Mencari Segi-segi Positif Fundamentalisme Islam, Penilita, (Jakarta), 18 Pebruari 1993, h. 4
} 
terapkan terhadap Islam oleh sebagian kaum muslimin. Meskipun istilah fundamentalisme tidak murni berasal dari sendi dasar ajaran islam melainkan bagian dari kerangka kerja kaum protestan konservatif di Amerika pada abad ke-20. Istilah fundamentalisme dipakai untuk menunjukkan ciri satu doktrin berdasarkan kitab injil, yang meliputi lima poin; (Kelahiran Yesus dari sang perawan; kebangkitan fisiknya; kitab injil yang tanpa salah; penebusan dosa dan kedatangan Kristus yang ke dua). Poin yang sejalan dengan kaum muslim hanyalah yang menyangkut ketidaksalahan kitab suci, tentu saja dalam Islam itu al Quran. ${ }^{4}$

Kecendrungan untuk menafsirkan teks-teks keagamaan secara rigid (kaku) dan literalis seperti yang dikemukakan oleh kaum fundamentalisme Protestan, ternyata ditemukan juga di kalangan penganut-penganut agama lain di abad 21 ini, karena itu tidaklah mengherankan jika sarjana-sarjana orientalis dan islamis Barat kemudian menyebut kecendrungan serupa dikalangan masyarakat muslim sebagai fundamentalisme Islam. ${ }^{5}$ Walaupun terdapat kecenderungan yang sama pemahaman keagamaan, kelompok fundamentalis lebih suka menyebut diri dan kelompoknya dengan ushuliyah islamiyah (asas-asas Islam), Bath al-Islam (kebangkitan Islam) atau juga dengan Harokah Islamiyah (gerakan islamiyah).

Istilah yang paling dekat dengan fundamentalisme dalam agama Islam itu adalah salafiyah. Salafiyah adalah istilah yang mengacu kepada sikap atau pendirian para ulama Islam dari generasi (generasi) salaf (yang paling awal). Dalam akidah mengacu kepada golongan ummat Islam yang bersikap dan berpendirian seperti yang dimiliki oleh para ulama dari generasi (generasi) salaf tersebut. ${ }^{6}$ Akan tetapi dalam praktik keagamaannya tidak merepresentasikan salafus shalih yang inklusif dan moderat.

Kaum fundamentalis cenderung menggunakan kekerasan dalam mencapai tujuannya dengan dalih kembali kepada Al-quran dan As-sunnah. Sikap eksklusif dan apologis menjadi ciri khas tak terbantahkan dalam setiap pemikirannya. Sehingga sikap ini menjadi semakin menguatkan pandangan miring orang diluar islam tentang fundamentalisme.

Ada beberapa kelompok islam yang bisa digolongkan fundamentalis, Pertama, fundamentalisme itu berupa oppositonalisme (faham perlawanan), kepada apa yang

\footnotetext{
${ }^{4}$ Riffat Hasan "Mempersoalkan Istilah Fundamentalisme Islam", Ulumul Qur'an, IV, 3, (1993), h. 33

${ }^{5}$ Yusril Ihza Mahendra. "Fundamentalisme Sebagai Corak Keberagamaan: Yayasan Paramadina, 74, (Mei 1993), h. 89

${ }^{6}$ Tim Penulis IAIN Syarif Hidayatullah ed, "Ensklopedi Islam Indonesia" Jakarta: Djambatan 1992). H. 831
} 
dipandang akan membahayakan eksistensi agama, apakah itu dalam bentuk modernitas, sekularisasi, dan tata nilai Barat pada umumnya. Acuan dan tolak ukur untuk menilai tingkat ancaman itu tentu saja adalah kitab suci, yaitu al Quran dan pada batas tertentu al Hadith. Kedua, penolakan terhadap hermeneutika. Dengan kata-kata lain kaum fundamentalisme menolak sikap kritis terhadap teks dan interpretasinya. Teks al Quran harus di pahami secara literal sebagaimana adanya, karena nalar tidak mampu memberikan interpretasi yang tepat terhadap teks. Ketiga, penolakan terhadap pluralisme dan relativisme. Bagi kaum fundamentalisme pluralisme merupakan hasil dari pemahaman yang keliru terhadap teks kitab suci. Pemahaman dan sikap keagamaan yang tidak selaras dengan pandangan kaum fundamentalisme merupakan bentuk dari relativisme keagamaan, yang terutama muncul tidak hanya dari intervensi nalar terhadap teks kitab suci. Tetapi juga karena perkembangan sosial kemasyarakatan yang lepas dari kendali agama. Keempat, penolakan terhadap perkembangan historis dan sosiologis, kaum fundamentalisme berpandangan, bahwa perkembangan historis dan sosiologis telah membawa manusia semakin jauh dari doktrin literal kitab suci. Bukan sebaliknya, teks atau penafsirannya yang mengikuti perkembangan masyarakat. Karena itulah, kaum fundamentalis bersifat a historis dan a sosiologis; dan tanpa perduli bertujuan kembali kepada bentuk masyarakat ideal seperti zaman kaum salaf yang di pandang mengejawantahkan kitab suci secara sempurna. ${ }^{7}$

\section{Asal-Usul}

Istilah fundamentalisme Islam dikalangan Barat mulai popular berbarengan dengan terjadinya revolusi Islam Iran pada tahun 1979, yang memunculkan kekuatan muslim syi'ah radikal dan fanatik yang siap mati melawan The great satan, Amerika Serikat. Setelah revolusi Iran, istilah fundamentalisme Islam digunakan untuk menggeneralisasi berbagai gerakan Islam yang muncul dalam gelombang kebangkitan Islam (Islamic Revivalism).

Akar sejarah fundamentalisme Islam muncul dari ideologi kaum oposisi, muncul sebagai senjata ideologis untuk melawan kelas penguasa yang dianggap zalim dan menyimpang dari ajaran Islam yang benar yaitu Al-quran dan As-sunnah.

\footnotetext{
${ }^{7}$ Azyumardi Azra, "Fenomena Fundamentalisme dalam Islam". Survei Historis dalam Doktrinal. Ulumul Quran, IV 3, (1993), h. 19
} 
Pada masa Rasulullah Saw. fenomena gerakan pemikiran dan sikap dalam beragama kelompok fundamentalisme sudah ada dan dipraktikan dalam kehidupan sehari-hari termasuk hal-hal yang berkaitan dengan politik kekuasaan. Kelompok inilah yang pertama kali menginiasi agama sebagai aspirasi politik bukan inspirasi. Sehingga seringkali agama dijadikan kendaraan politik meraih kekuasaan. Kelompok ini muncul ketika terjadi konflik antara Ali bin Abi Thalib dan Muawiyah. Mereka berpandangan bahwa kedua antara Ali bin Abi Thalib dan Muawiyah adalah kafir karena tidak menegakkan hukum sesuai dengan hukum Allah seperti yang ada dalam Al-quran.

Kecenderungan fundamentalisme sebagai ideologi oposisi memang terasa hingga ke pertengahan abad ke 21 ini, ditengah kecenderungan rezim demokratis yang dinilai cenderung bermusuhan terhadap Islam dan melaksanakan berbagai kebijakan yang dianggap bertentangan dengan nilai-nilai Islam, merupakan perangsang yang kuat bagi kebangkitan gerakan fundamentalisme.

\section{Doktrin}

Istilah fundamentalisme bukan suatu hal yang mudah diterapkan dilingkungan umat Islam, jika istilah itu diartikan sebagai paham yang bersangkutan dengan ajaran dasar Islam $^{8}$ seperti yang ada dalam pemikiran mereka. Akan tetapi bagi kaum fundamentalisme doktrin sebagaimana yang terdapat di dalam al Quran adalah doktrin yang bersifat universal dan telah mencakup segala aspek dalam kehidupan manusia dan tidak dibatasi oleh ruang dan waktu. Oleh karena itu ijtihad harus di batasi demi menjaga kemurnian doktrin dan pelaksanaannya. Kalaupun ijtihad harus dilakukan, terbatas kepada persoalan-persoalan teknis dalam kehidupan sehari-hari. Dan untuk menjaga agar ijtihad sesuai dengan maksud dari nash Alquran dan al Hadith, maka upaya itu hanya boleh dilakukan oleh alim ulama yang benar-benar telah memenuhi syarat-syarat untuk menjadi seorang mujtahid.

Fundamentalisme berkecenderungan doktriner yang dilandasi oleh motif untuk memahami dan mengamalkan doktrin secara murni dan bebas dari interpretasi. Mereka menginginkan ajaran islam persis sama dengan apa yang telah dilakukan oleh Rasulullah tanpa peduli tempat, kondisi, dan situasi agama islam berada. Sikap yang

\footnotetext{
${ }^{8}$ M. Dawam Raharjo, "Fundamentalisme Sebagai Corak Keberagamaan". Yayasan Paramadina. 74 (Mei 19930 h.74
} 
demikian berpotensi menimbulkan kesan dan preseden buruk bagi citra islam yang dinilai tidak bisa mengakomodir perkembangan zaman.

Pilhan sikap beragama yang dianut oleh kaum fundamentalisme umumnya cenderung bersikap negatif dan pesimis terhadap kemajemukan. Dalam arti kemajemukan etnik, cultural, bangsa dan agama, di samping itu juga kemajemukkan corak keberagaman di kalangan kaum muslimin. Seperti membedakan masyarakat di dunia ini menjadi dua jenis masyarakat, yaitu masyarakat Islami (al Nizam al Islami) dan susunan masyarakat jahili (al Nizam al jahili. Susunan masyarakat Islam dipandang sebagai masyarakat yang benar-benar melaksanakan tuntunan doktrin secara kaffah (total), dan karena itu bersifat ilahiyah (ketuhanan). Masyarakat yang tidak bercorak demikian semuannya tergolong jahili dan karenanya bersifat taghut (berhala). Kaum fundamentalis berpandangan bahwa tegaknya hukum Allah dan As-sunnah hanya dapat dilaksanakan dengan memiliki negara Islam dengan sistem khilafah.

\section{Tipologi Fundamentalisme}

Fundamentalisme dalam Islam dapat di bagi menjadi dua tipologi yaitu pra modern dan kontemporer (Neo Fundamentalisme). ${ }^{9}$ Pertama, fundamentalisme pra modern atau klasik, merunjuk kepada satu gerakan yang menuntut kepatuhan yang mutlak kepada al Quran dan as Sunnah, yang menjadikan standar nilai dan dasar-dasar kepercayaan yang tidak berubah.dan hal ini mesti diterima oleh setiap masyarakat Islam. ${ }^{10}$ Kaum khawarij yang muncul pada periode Islam, atau gerakan-gerakan sepanjang pemerintahan dinasti Abbassiyah yang dipelopori oleh Ahmad ibn Hambal (780-885). Ibnu Taimiyah, Muhammad, Ibnu Abdul Wahab dapat digolongkan dalam gerakan ini, dan semata-mata lahir karena faktor internal umat dan tidak ada hubungannya dengan pengaruh Barat.

Tokoh yang sangat lantang menyeru orang, baik dengan lisan maupun tulisan, agar berakidah dengan akidah salaf adalah Ibnu Taimiyah (1263 - 1328 M/661 - 728). Hal yang paling di tekankannya dalam usaha pemurniannya adalah agar ummat Islam membuang jauh sifat fanatisme dan kejumudan. ${ }^{11}$

Jalan pikirannya selalu terkait dalam ruang lingkup al Quran dan Hadith. Oleh sebab itu pembuat, bid'ah dan khurafat merupakan musuh utama yang hendak dihabisi. Ia

\footnotetext{
${ }^{9}$ Yusril Ihza Mahendra, Op. Cit, h 32 - 33

${ }^{10}$ Ilyas Ismail, Loc. Cit.

${ }^{11}$ Tim Penulis IAIN Syarif Hidayatullah . Op. cit, h. 832
} 
menjunjung tinggi supromasi al Quran dan al Hadith sebagai dasar yang mengatur kehidupan sosial dan politik masyarakat. Pemikiran dan usaha reformasinya selain dari aqidah juga kepada hukum, politik dan filsafat. Ia juga mengecam dan menyerang sufi, mutakalim, dan filosof yang dianggapnya telah merusak aqidah Islam.

Gerakan-gerakan diatas memperlihatkan cirri-ciri umum antara lain: memiliki keprihatinan yang mendalam terhadap kemerosotan sosial moral masyarakat muslim: menghimbau untuk kembali kepada keIslaman yang orsinal, menanggalkan tahayultahayul yang ditanamkan dalam bentuk-bentuk sufisme. ${ }^{12}$

Kedua, fundamentalisme kontemporer (neo fundamentalisme), merupakan kelanjutan dari fundamentalisme klasik, fundamentalisme ini timbul selain karena faktor internal ummat. Juga karena masuknya pengaruh budaya dan pemikiran Barat kedunia Islam. Fundamentalisme modern tumbuh subur dan berkembang pesat di mesir dalam bentuk gerakan ikhwan al Muslimin (The Muslim Brotherhood) yang didirikan oleh Hasan al Banna di Mesir pada tahun 1928, dan dalam gerakan Jama'at al Islami yang didirikan oleh Abu al A'la al Maudidi di India. ${ }^{13}$ Misalnya Maududi, pemimpin partai jamaat al Islami, yang memperjuangkan idiologi Islam sesuai dengan tuntunan Rasulullah, menurutnya pemimpin gerakan Islam itu sebagai khalifah yang mesti dipegang oleh seseorang yang memiliki pengetahuan keagamaan dengan derajat yang tinggi.

Tujuan partai ini adalah untuk menegakkan kedaulatan Tuhan di muka bumi dan menegakkan Islam sebagai jalan hidup bagi ummat manusia. ${ }^{14}$ Contoh yang lain adalah Ikwanul Muslimin yaitu sebuah gerakan Islam yang aktif mempromosikan dan menerapkan ajaran agama berdasarkan al Quran dan Hadith secara ketat dalam kehidupan ummat. Pada intinya al Banna merumuskan ideology Ikhwanul Muslimin yang menekankan kemampuan Islam sebagai ideology yang total dan komprehensif, program Ikhwanul Muslimin kemudian didasarkan pada tiga pandangan dasar, yaitu; pertama, Islam adalah sistem komprehensif yang mampu berkembang sendiri (mutakamil bi dzatihi); ini merupakan jalan mutlak kehidupan dalam seluruh aspeknya. Kedua, Islam memancar dari dua sumber fundamental, yakni al Quran dan al Hadith. Ketiga, Islam berlaku untuk segala waktu dan tempat.

\footnotetext{
${ }^{12}$ Fazlur Rahman, "Perkembangan Modern dalam Islam, Gerakan Pembaharuan dalam Islam di tengah Tantangan Dewasa ini. (Jakarta : Yayasan Obor Indonesia, 1985). Cet I. h. 22

${ }^{14}$ Yusril Ihza Mahendra, "Maududi dan Jama'at al Islami, Pembentukan dan Tujuan Partai Fundamentalisme". Ulumul Quran, IV, 3 (1993), h. 33.
} 
Disamping itu Ikhwanul Muslimin mempunyai dua program yang cukup bagus. Yaitu Internasionalisasi organisasi. Guna membebaskan seluruh wilayah muslimin dari kekuasaan dan pengaruh asing. Kedua, membangun diwilayah muslimin yang telah di bebaskan dengan mempratekkan prinsip-prinsip Islam dan menerapkan system sosialnya secara menyeluruh. ${ }^{15}$ Diantara tugas Ikhwanul Muslimin adalah membendung peradaban materialistis dan kebudayaan yang telah menghanyutkan bangsa-bangsa muslim dan menjauhkan dari sifat kepemimpinan Nabi Muhammad serta hidayah al Quran. Sebab peradaban dan kebudayaan telah menghalangi dunia dari sinar al Quran dan menyeret dunia kelembah keterbelakangan hingga beberapa abad. ${ }^{16}$

Ikhwanul Muslimin menghendaki individu, rumah tanggah, rakyat, pemerintah dan negara muslim, yang dapat memimpin eksistensi negara-negara Islam guna mempersatukan umat Islam dan medudukkan ajaran Islam secara benar. Semanggat Ikhwanul Muslimin tidak lepas dari semanggat pendirinya, yaitu Hasan al Banna yang khas yaitu. Sungguh keliruh anggapan yang menyatakan Islam hanya terdiri dari aspek rohaniah dan ibadah. Islam bukan hanya doktrin agama yang menyangkut aspek kerohanian dan penyembahan, melainkan juga meliputi semangat kebangsaan, tanah air. Semangat dan pemahaman keislaman seperti inilah yang dijadikan tema utama dakwahnya, yaitu dalam hal akhidah dan syari'at. Selain mengajak umat untuk kembali kepada sumber utama ajaran Islam, al Quran dan al Sunnah, juga berusaha menghapuskan pertentangan-pertentangan kemazhaban, terutama dalam mazhab fiqh. Corak keberagamaan demikian memang lahir sebagai respon sesuai dengan kondisikondisi lingkungan yang mempengaruhinya. Jadi selama factor-faktor eksternal ataupun internal itu ada, maka selama itu pula corak keberagamaan fundamentalisme akan tetap ada, walaupun dimasa depan mungkin akan mengambil bentuk-bentuk baru sesuai dengan tantangan yang muncul dimasa yang akan datang.

\footnotetext{
${ }^{15}$ Azyumardi Azra, Loc. Cit, 21 - 22

${ }^{16}$ M. Hilmy. Al Manyawi. "Pidato dan Surat-surat Hasan al Banna". (Bandung: Risalah. 1984). Cet. Ke- 1. h. 68
} 


\section{Penutup}

Fundamentalisme dalam islam sejatinya tidak mempunyai akar sejarah yang kuat baik dari fikrah (pemikiran) dan harakah (gerakan). Fundamentalisme adalah produk kekinian yang kental dengan kepentingan sepihak (vested interest). Jargon "kembali kepada Alquran dan hadits" dan "khilafah", yang diusung hanya sebatas pemantik agar masyarakat islam tertarik dan bergabung dengan mereka. Kekakuan dalam menginterpretasi maksud yang terkandung dalam wahyu ilahiyah menjadi ciri khas pemikiran fundamentalis yang berujung pada sikap keagamaan yang takfiri (mengkafirkan orang lain yang muslim) dan . eksklusive. 


\section{Daftar Pustaka}

Azra, Azyumardi, "Fenomena Fundamentalisme dalam Islam”. Survei Historis dalam Doktrinal. Ulumul Quran, IV 3, 1993.

Hasan, Riffat. “Mempersoalkan Istilah Fundamentalisme Islam” , Ulumul Qur'an, IV 3, 1993.

Hilmy, M. Al Manyawi. "Pidato dan Surat-surat Hasan al Banna”. Bandung: Risalah. 1984.

Ismail, Ilyas, "Mencari Segi-segi Positif Fundamentalisme Islam, Penilita, Jakarta. 1993.

Ka'bah, Rifyal, Busthani Said, "Reaktualisasi Ajaran Islam: Pembaharuan Agama Visi Modernis dan Pembaharuan Agama Visi Salaf. Jakarta : Minarei, 1987.

Ka'bah, Rifyal. "Modernisme dan Fundamentalisme Ditinjau dari Konteks Islam", Ulumul Quran, IV, 31993.

Mahendra, Yusril Ihza, "Maududi dan Jama'at al Islami, Pembentukan dan Tujuan Partai Fundamentalisme”. Ulumul Quran, IV, 31993.

Mahendra, Yusril Ihza. "Fundamentalisme Sebagai Corak Keberagamaan: Yayasan Paramadina, 1993.

Raharjo, M. Dawam, "Fundamentalisme Sebagai Corak Keberagamaan". Yayasan Paramadina. 1993. 